\title{
6 \\ Innovating training and development in government: The case of South Korea
}

\section{Pan Suk Kim}

Innovating training in government is an important topic for human resource development, and is an especially timely subject in this era of globalisation and the information society. This chapter is a personal reflection on civil service training in Korea, what makes it unique, and how it can be strengthened. The author draws upon broad experience, as both an academic and practitioner, in the field of public policy. The chapter outline is as follows. A general overview of performance management, human resource management (HRM), human resource development (HRD), training development and learning will first be provided. This will be followed by an introduction to the training system in the Korean Government, and a discussion of the Korean Government's experience of training innovation. Before concluding, lessons learned in overcoming resistance to training and in searching for the future direction of training innovation will be addressed.

In an era of globalisation, regional and global competition have increased, while budgetary cuts affected by current global economic stagnation are an unavoidable reality around the world. In such challenging circumstances, performance management is becoming a popular term and a new organisational ideology across the world. 
Performance management starts with establishing performance standards, identifying relevant standards and selecting an indicator index. Performance measures then need to be decided, indicators refined and measures defined. There must be improvements to the process, the use of data for decisions to improve policies, programs and outcomes and then, of course, to progress reporting.

In certain countries, performance may not be well understood or institutionalised. To institutionalise performance management, it is necessary to provide performance awareness (to allow roles and responsibilities to be understood and performance expectations to be set and reviewed) from the outset. Performance awareness is critical for promoting an organisational culture that will adopt a performance system. When people are increasingly aware of performance, they can keep track of and identify what they should do and focus on their goals. Subsequently, a performance-focused attitude along with strategic alignment can be developed. Organisational goals should be translated into individual and team goals and the performance management process should be linked to the execution of other organisational strategies.

In performance management, because human resources and human capacity are critical, it is necessary to review HRM in a broader sense. In the human resource cycle, there are two elements: HRM and HRD. To summarise, HRM is made up of many functions, including obtaining and maintaining $\mathrm{HR}$ and developing employees, HR planning, performance management systems, selection and staffing, compensation and benefits, employee assistance, union labour relations, HR resources and information systems. In addition to these are HRD functions, such as training and career development and organisational job design. While HRD comprises several elements, this chapter will focus on training and development (Kang et al. 2011).

\section{Areas and stages of training and development}

Training and development (T\&D) include several relevant areas: 1) training; 2) education; 3) development; and 4) learning. Training refers to acquisition of 'knowledge, skills, ability, values and attitude' 
(KSAVA) by workers to perform their jobs better. It is more or less formal, organisation-based and somewhat technical, and is related to a person's present job. On the other hand, education focuses on the jobs that the individual may potentially hold in the future. Development refers to the activities of an organisation employing an individual or that the individual is part of, or may partake of in the future. In addition, learning has become a commonly used term, referring to the process of acquiring new, or modifying existing, knowledge, behaviours, skills, values or preferences, and may involve synthesising different types of information. It is individual and/or organisation based; learning occurs as part of personal development, education, training, work or exercise. Overall, learning is a much broader term than training. Learning could be defined as a function of observation or experience, plus practice or experimentation, and supported by reinforcement. Reinforcement here means that something is reinforced through positive and negative incentives or disciplines.

There are several prevailing theories on learning. Social Learning Theory (SLT) approaches the explanation of human behaviour in terms of a continuous reciprocal interaction between cognitive behaviour and environmental determinants. Determinants of human behaviour include cognitive factors (knowledge, expectations and attitude), behavioural factors (skills, practice and self-efficacy) and environmental factors (social norms, access in a community, influence on others), and all these factors determine human behaviour. Other learning theories include behaviourism, constructivism, cognitivism and connectivism. These theories lead to a number of questions: how does learning occur? What factors influence learning? How does transfer occur? Comparing all these theories is not an easy task, but a simple summary of the factors influencing learning is as follows.

- Behaviourism argues that the factors facilitating learning are natural stimuli, reward and punishment.

- Cognitivism believes that learning hinges on existing schema and previous experience.

- Constructivism premises learning on engagement and participation.

- Connectivism argues that the key to learning lies in the diversity of workers. 
While various terms are used in the field, as discussed in the previous section, the most commonly used term in government is still training. Training has a number of phases, each of which includes additional processes.

- Analysis: Skill gaps need to be identified, such as gaps between needs and the current situation, which then requires a needs analysis.

- Design: HRD strategy as well as strategy in design must be evaluated. Blended solutions - combining a number of solutionsshould be considered. Design should be structural, including blending and learning management.

- Development: Here, material development, performance support and training the trainer are important.

- Deployment: Training delivery, an exclusive training portal site (a simple web-based system that automates many of the processes involved in training management and administration), program management and flexible resourcing are needed in this phase.

- Evaluation: There is a need to evaluate reaction, evaluate learning, evaluate behaviour and performance or business benefit or return on investment (ROI).

- Feedback: Feedback follows evaluation, and includes lessons learned, revising strategies and continuous improvement.

To innovate training, there should be a review of each phase, looking to improve any weaknesses or reduce limitations. Explaining all these phases in detail is beyond the scope of this chapter.

\section{The Korean Government training system}

\section{Legal foundations}

The Korean Government has a strong legal foundation for training, which is evident in several training laws and decrees. For example, Article 50 of the Civil Service Act of 1949 deals with training. In 1961, the government promulgated a separate Training Act for civil servants. Such distinct and dedicated legislation for training civil servants is unique to Korea since, while many countries have their own civil 
service laws, most do not have a separate law relating specifically to training (Kim and Kim 1997; Kim 2009, 2010, 2011). As we will see, this legislative approach, coupled with a strong emphasis on adopting international best training practice - from the public but also private sectors - is unique to the Korean training experience.

Table 6.1: Korean Government legislation relating to training

\begin{tabular}{|l|l|}
\hline 1949: & Promulgated the Civil Service Act (Article 50) \\
\hline 1961: & Promulgated the Training Act for Civil Servants \\
\hline 1961: & Promulgated the Training Decree for Civil Servants \\
\hline 1961: & $\begin{array}{l}\text { Promulgated the Act for the Establishment of the Central Officials } \\
\text { Training Institute }\end{array}$ \\
\hline 1963: & Promulgated the Local Civil Service Act \\
\hline 1973: & Promulgated the Education and Training Act for Civil Servants \\
\hline 1973: & $\begin{array}{l}\text { Promulgated the Education and Training Decree for Civil Servants } \\
\text { (after the re-establishment of full-scale local autonomy) }\end{array}$ \\
\hline 1995: & Promulgated the Education and Training Act for Local Civil Servants \\
\hline 1995: & Promulgated the Education and Training Decree for Local Civil Servants \\
\hline 2015: & $\begin{array}{l}\text { Revised the Education and Training Act for Civil Servants and renamed } \\
\text { it the Talent Development Act for Civil Servants }\end{array}$ \\
\hline 2016: & $\begin{array}{l}\text { Revised the Education and Training Decree for Civil Servants and renamed } \\
\text { it the Talent Development Decree for Civil Servants }\end{array}$ \\
\hline
\end{tabular}

On the basis of the Training Act, the Korean Government promulgated related decrees, including the 1961 Training Decree for Civil Servants. Particularly noteworthy is the Act for the Establishment of the Central Officials Training Institute (COTI) of 1961, which expanded the National Officials Training Institute (NOTI) set up in 1949 with technical support from the US International Cooperation Agency. In 1973, the Korean Government renamed the Training Act to the Education and Training Act for Civil Servants. By adding the term 'education' to the title, the government underscored its intention to enhance the capacity of civil servants. Moreover, when Korea re-established full-scale local autonomy in the 1990s, the government promulgated the Education and Training Act for Local Government Civil Servants as well as the corresponding decree. Thus, the Korean Government has a number of rules and regulations related to the training of government employees. 


\section{Training institutes}

In terms of the organisational foundation for training, training policy is handled by the Division of Education and Training in the HRD Bureau of the Ministry of Public Administration and Security (MOPAS). ${ }^{1}$ While there are many training institutes in the government, one of the most important is the COTI. ${ }^{2}$ As the main training institute under MOPAS, COTI's mission is to develop highperforming government officials by providing general and specialised training, and to serve as a support centre for other public service training institutes across Korea. It also seeks to widen Korea's global network through international training and exchange activities with recognised overseas institutions. The head of COTI is a vice-minister overseeing several departments such as Planning, and Education and Training. The Planning Department in turn has many divisions, as does the Education and Training Department. In addition, COTI has a consulting and advisory group, as well as a recently launched research and development centre. Altogether, COTI employs approximately 150 full-time staff.

There are various public service training institutes in other central government agencies. Many provincial-level governments also have their own training institutes. In 1965, the Local Administration Training Institute (LATI) was established to provide learning and development for senior local government officials. This institute is now known as the Local Government Officials Development Institute (LOGODI), ${ }^{3}$ and provides training programs for about 40,000 participants every year.

The Korean Government requires all civil servants to undertake grade-based basic (foundation) training before they can be considered for promotion or appointment. In addition, all public officials are encouraged to undertake specialised training programs to increase their knowledge and skills, to carry out their functions effectively in their respective fields. Training should also meet the needs of individuals and be aligned with relevant organisational goals and objectives. Training should be a vigorous aspect of innovative performance management. In addition, the recently added Article 11

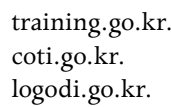


of the Education and Training Decree for Civil Servants emphasised that training is the joint responsibility of the officer and their supervisor. This seeks to rectify some supervisors' reluctance to release staff for training amid the focus on attending to their core work.

\section{Training programs}

The key training program in the Korean bureaucracy is the Senior Executive Program for senior civil servants (SCS), the highest level in the Korean Civil Service. The Korean Civil Service comprises nine grades, with Grade 9 the lowest and Grade 1 the highest in the hierarchy. SCS candidate development programs exist for Grades 3-4, divisional candidate development programs for Grade 4, which is a senior official's entry course, and newly promoted or appointed managers' courses are for Grade 5. At lower levels, there are training programs for Grades 7 or 9 recruited through open competitive examination. Middle to low-level government employees can access a learning program called 'Learning at All Times'.

Officers from Grades 4 to 9 are responsible for taking 100 hours or more of training annually, with 40 per cent of the learning hours devoted to work-related development and 60 per cent to personal development. The 40 hours of work-related development should correspond directly with job function and responsibilities, and officers can choose to meet this requirement through training at public or private institutions. The 60 hours of personal development could support job performance but need not be directly related to job functions - for example, a language course in French or Spanish, which might not be directly related to the job function, but satisfies the personal development function.

A criticism of this policy is that the amount of training time does not guarantee the quality or effectiveness of the training. It should be noted that governments often forget to research the outcomes needed, and so train people in unnecessary areas. This results in people with skills and knowledge that are not useful to them in job seeking, in making their job easier, in making them more useful to the organisation or in gaining promotion; it is thus a waste of resources that should have been better used. 
In summary, there are three types of training programs for civil servants. Basic foundation-grade courses are delivered by public service HRD centres. Specialised courses, such as task-related, language or information communication technology (ICT) courses, are delivered by public HRD centres as well as domestic or overseas institutions commissioned by government agencies. Other courses, such as civil service ethics, integrity, training on government policy, public values (de Vries and Kim 2011) and individual learning research activity, can be delivered by public or private HRD centres. Thus, the training market has been opened up, with many private vendors delivering training for government employees.

\section{Recommendations for innovation in the Korean Government training system}

The general assumption is that there is no one 'best' strategy or method in training; to promote HR capacity, training systems and training programs should be continually improved. The public perception of government training has not been good and continuous improvement in training needs to be promoted. An immediate step towards this is to organise a reform team comprising a combination of internal and external experts, with strong support from the head of statein Korea's case, the President.

A recent Korean experience of training innovation is outlined, based on the author's firsthand involvement in the process. In 2004, the author was invited to assume the position of secretary to the President for personal policy in the Office of the President (the so-called Blue House). In this capacity, he organised an innovation taskforce for training. This taskforce comprised directors-general (DGs) or senior officials of the Civil Service Commission (CSC) and the Ministry of Government Administration and Home Affairs (MOGAHA), DGs from major training institutes, including COTI and LOGODI, and experts from outside government, such as professors and research institute experts. Over numerous meetings, this taskforce conducted a joint comparative study and visits to domestic private companies, HRD centres and foreign government training institutes. Overseas visits included trips to the Federal Executive Institute (FEI) in Virginia, USA, and General Electric (GE) Company's training and development 
institute. A particular standout was GE's John F. Welch Leadership Development Centre established in 1956 in Crotonville, New York. ${ }^{4}$ For more than 50 years, the centre has been at the forefront of real-world application for cutting-edge thinking in organisational development, leadership, innovation and change. Every year, thousands of GE employees, from entry-level workers to the highestperforming executives, journey to Crotonville for a transformative learning experience that, for many, becomes a career-defining event. GE's Corporate Entry-Level Leadership Programs offer recent college graduates prized development opportunities that combine real-world experience with formal classroom study. Experienced professionals who wish to accelerate their careers can participate in the Experienced Leadership Programs. Today, the Welch Leadership Centre serves as a powerful organisational force reminding each GE employee to never stop learning.

From this experience, a report was finalised and presented to the Korean President, key ministers and senior advisors. After the presentation, the President directed the then chairman of the CSC to implement the necessary training reform measures. At the same time, the President asked the finance minister to allocate an additional budget for training innovation. Consequently, many more training manuals, case studies and new methodologies were developed. For several months, biweekly team meetings sought to develop and implement reform measures. Moreover, each training agency had its own dedicated meeting for its own innovation.

COTI in particular had numerous meetings for low-level workers such as security guards at government buildings and cooks in the cafeterias. In order to innovate reform at the training institute, everyone was expected to do something new or better. While it is typically presumed that training reform is initiated by senior officials looking to improve training methodology and the development of trainers, in COTI's case, almost everyone was involved. For example, after reform, security guards who used to remain at their posts began instead to greet visitors to the building. Likewise, through the reforms, cooks were able to raise the quality of their food to compare with that of restaurants. Drivers who pick up staff and trainees received external 
lecturers from Seoul and the suburbs. Administration staff started to come out of their offices to engage with external lecturers and trainees, and to survey the quality of training methodology. Researchers were able to develop better case studies, training modules and manuals, to provide stronger teaching support and administration staff. And of course, trainers were delivering better methods and improving the quality of their materials. Hence, everyone from trainers, planners and cooks to security officers, drivers and administrative staff-indeed, every member of the training institute - was encouraged to come up with new ideas to improve the quality of their preparation, planning, training and methodology, right down to the general quality of service. In sum, the training innovation in COTI started with everyone and not just a few reform agents.

In addition, the Korean Government initiated a special program to learn how to manage failures in public administration. Traditionally, the government paid little attention to learning from failures, yet there are a lot of cases of failure that offer lessons so that future mistakes can be avoided or better managed. A case in point is how lessons in public communication and conflict management can be drawn from several environmental projects where residents, in a manifestation of the 'not-in-my-backyard' attitude, refused to accommodate the establishment of a dumping ground in their vicinity.

An enabling social environment needs to be created for innovation and an accelerated learning culture, whereby various learning methods and programs will be adopted. Efforts to develop a learning and development culture should be pursued seriously in government. Those involved should progress through various learning programs and methods, such as workshops, physical exercises, and on-site and action learning. Learning and training are not just for middle or lowlevel employees, but are also necessary for higher-level executives, such as ministers and vice ministers. We particularly emphasise that training is needed for government executives: ministers and deputy ministers. Needless to say, training for government executives would not be the traditional classroom kind of training, but ministers and deputy ministers can have flexible learning programs such as dialogues, seminars or workshops. 
It is also necessary to promote government employees' active and voluntary participation in learning communities. The Korean Government supports dong-a-ri, which refers to a group of people learning or a study group in government. Dong-a-ri guides formal as well as informal groups in solving problems. Also, various learning systems need to be established, such as action learning and mentoring. There needs to be a cultural change to utilise training programs to promote an innovative culture. In other words, HRD or training could become a part of government reform strategies. Learning organisation also needs to be built up and perhaps high-impact organisation can be chosen. Not many governments have a workshop involving the President, but Korea has the National Agenda Workshop, which was introduced during the Roh Moo-Hyun administration (2003-08). The President presides over this workshop, which often takes place at COTI and includes ministers and high-level officials. It is a dialogue between participants, to build team spirit and to understand each other. Sometimes the National Agenda Workshop becomes the basis for setting national priorities and building consensus. This is a unique kind of program for government executives. The training of top civil servants is underdeveloped in many countries, and this is a program that should be better developed in the future. However, there is relatively little public discussion on the nature of training for top civil servants (Pollitt and Op de Beeck 2010).

\section{Additional recommendations for innovation}

There are a number of different training methodologies, but a lecture is considered less effective, while the most effective method is teaching others (a person has to know the content in order to teach it). Other effective methods include practise by doing, discussion groups, demonstration, audiovisual presentations and reading to a lecture. According to the Annual Survey Report of the UK Chartered Institute of Personnel and Development (CIPD 2007), the most frequently used learning methods were: on-the-job training, in-house development programs, instructor-led training delivered off the job, external conferences or workshops, formal education courses, coaching by line managers, internal knowledge-sharing events, e-learning, audiotapes and videos, mentoring and buddying schemes, coaching by external practitioners, job rotation and secondments, and action learning settings. 
We also need to increase training budgets. Governments must allocate substantial funds for training. The Korean National Government's training budget was approximately A $\$ 194.4$ million in 2006. By comparison, one of Korea's multinational companies had a training budget of A $\$ 252.5$ million - a far higher investment in training than the government's. A comparison with GE indicates even greater disparity: GE invests about $\mathrm{A} \$ 1.3$ billion each year in training and education programs for its employees. ${ }^{5}$ The Korean Government's training budget is relatively small compared with those of multinational companies, and should be increased. Government executives and senior managers should have more responsibility for allocating funds for training. However, this issue could be dependent on the organisational structure and status of the training and development institute (Pollitt and Op de Beeck 2010); in some countries, funds come mainly from universities or independent institutes (that may operate on market principles), while in others, there are public agencies at arm's length from the central ministries and departments, or a national school with close ties to the Central Government (they may be partly or largely subsidised by funding from the relevant public agencies or have guaranteed financial allocations). Nonetheless, current economic conditions could affect funding for training and learning. Since many people are not optimistic about a quick economic recovery, the government should prepare for such challenges.

The cost of tuition for public service training in many Asian countries is too low; in some countries, trainers are paid almost nothing. In comparison, the cost of tuition in North American and European countries is substantially higher. Training elites is not cheap; in the United States, for example, two-week programs for government employees at the FEI cost almost A $\$ 7,900 .{ }^{6}$ In the United Kingdom's National School of Government, the Modern Leaders Program costs $\mathrm{A} \$ 8,600$ for just one day. Thus, it is necessary to price tuition costs appropriately; a cheap program cannot produce high-quality results.

Moreover, poor compensation for trainers and lecturers must be changed. The Trainers and Development Institute (TDI) should not be a HR 'dumping ground' for low performers. TDI should have highly competent trainers and motivated administrative staff. Although a

5 ge.com/company/culture/leadership_learning.html.

6 leadership.opm.gov. 
highly priced course is no guarantee of quality content and delivery, it is necessary to pay at least a reasonable level of compensation to trainers and lecturers. If we want to attract the best staff, we must pay attractive wages. As a general principle, better-paid, quality lecturers and trainers should deliver better training.

It would also be useful to develop and utilise a competency framework, which many organisations in the world now have in place. The Korean Government has a competency framework with three dimensions: thinking, working and building relationships. In the thinking dimension, the emphasis is on problem awareness and strategic thinking; the working dimension focuses on results and change management; and the building relationships dimension looks at customer satisfaction and coordination of integration. Commonly needed skills might include communication, people management, team and customerservice skills, problem-solving and technical skills. In order to assess a person's competency, various methodologies (group discussion, roleplay, presentation and interview) are used. Competency assessment usually takes most of a day and evaluators carefully observe all participants before finalising competence assessment. This provides an opportunity to improve skill deficiencies in those who fail to pass the assessment procedure. This is not a symbolic exercise; the Korean Government had a failure rate of 14.5 per cent in 2009. Such a striking result caused many government officials to pay more attention to their education and development. Increasing numbers of government officials in Korea are now returning to a tertiary institution to upgrade their education.

\section{Overcoming resistance to training}

People know that training is good for one's development, but not everybody welcomes training. There is a substantial degree of cynicism and distrust from employees as well as managers. Employee cynicism may stem from their distrust of the training's effectiveness or of the training institution, and their awareness that training may lead to them losing an opportunity for promotion. Additionally, they may worry about the potential loss of opportunity or human connections that comes from spending time away at a training institute. Negative views from managers include distrust of the effectiveness of training 
at a given institute, concern about staffing shortages while employees are away and a potential delay in the completion of work tasks. Other reasons include: competing business pressures; lack of understanding about the value and impact of training; perceptions of learning as optional or peripheral rather than essential; lack of senior management commitment and positive role-modelling; and lack of training for managers. Also, the pressure of time is by far the most common barrier to training and learning in organisations (CIPD 2007).

It is necessary to overcome these kinds of resistance to training. What solutions exist to reduce resistance? First, it is necessary to advocate training to employees and managers. It is also necessary to enhance the awareness of benefits among employees and managers and promote the importance of training. Clear messages about the importance of training and learning should be delivered to managers. Managers should be rewarded for developing the skills of their team members; senior managers should be encouraged to act as role models; and staff development should be included in line managers' annual performance objectives. It would also be good to reflect on training results in relation to job placement, promotion and new appointments. Moreover, it is necessary to reflect on training needs and expectations through voluntary participation (self-selection) or e-HRM along with ICT applications. Finally, it is necessary to improve the quality of training and provide a pool of HR substitutes.

\section{Conclusion: Future directions for the development of training}

It is time for a paradigm shift in training and education-from provider-centred programs to customised or tailored programs that are trainee-centred; and from theory-centred programs to those that are participatory or involve training by experience. We need innovation for better training development, so it is necessary to transform knowledge delivery into a curriculum centred on problem-solving. We need to change from simple evaluation of instruction to evaluating the outcomes of training. We also need to have continuous evaluation starting from the identification of needs through to application. A typical evaluation method is to survey the satisfaction levels and collect comments from the trainees, but a better method would be 
to assess the longer-term impacts of training (how, and how far, it affected the behaviour of the trainees once they had returned to their agencies).

So what are some future directions for the development of training? First of all, we need to recognise that training should be perceived as an investment, rather than a cost. It is an employee's right to have training or development opportunities. We need to secure the right to choose appropriate and necessary training courses and to utilise various training methodologies - not only lectures, but also participatory and experiential training methodologies.

We need to improve training conditions. We need better trainers, better facilities and better equipment. We need to have training evaluation and feedback for trainers and trainees. Training results should be utilised for employees' placement or promotion. There must be innovation in the operation of training institutes. For example, the head of each training institute should be recruited in an open, competitive way, and he or she must be reform-minded and reformorientated. It is therefore necessary to develop an open recruitment system to hire key officials and staff of training institutes; we need to turn those institutes into organisations that promote organisational learning to meet future challenges in government.

Finally, it is necessary to recognise that the nature of current public administration is becoming more complex, diverse, fragmented, interdependent, time-consuming, boundary-blurring and decentralised, with more stakeholders and an increasing number of dilemmas. In dealing with public affairs, many stakeholders are participating and conflicts are often developing, giving rise to an increasing number of 'wicked' problems. Capacity is fixed like a cup, but the challenges are growing and daunting, so we cannot hold them all. In other words, a small cup cannot hold all the things that overflow from a bigger bucket; a significant 'capacity deficit' can certainly be seen in the wide gap between growing demand and existing public capacity. In fact, public capacity has declined due to the shrinking role of the state, the more complex nature of problems, a lack of financial and human resources, the increasing cost of cooperative and communicative governance, the increasing number of critical citizens and a culture of resistance, as well as increasing public expectation. There is an urgent need for capacity building, but capacity building 
has three different levels: individual, organisational and systemic. At the individual level, the need is to improve the level of training and education. At the organisational level, the need is to improve the capacity of the organisation in its structure and management. At the systemic level, there is the need to improve the capacity of the system in modernising or innovating - for example, financial and legal systems. In an era of globalisation, and in a rapidly changing information society, we clearly need to innovate training and development in government. After all, government competitiveness is highly dependent on human capacity.

\section{References}

Chartered Institute of Personnel and Development (CIPD) 2007. Annual Survey Report on Learning and Development. London: UK Chartered Institute of Personnel and Development.

de Vries, M. and Kim, P. S. 2011. Value and Virtue in Public Administration: A comparative perspective. London: Palgrave.

Kang, S. C., Kim, P. S., Lee, J. S., Jin, J. G. and Choi, G. Y. 2011. New Public Personnel Management. [In Korean]. Seoul: Daeyoung Moonhwasa.

Kim, B. W. and Kim, P. S. 1997. Korean Public Administration: Managing uneven development. Seoul: Hollym.

Kim, P. S. (ed.) 2009. Public Administration and Public Governance in ASEAN Member Countries and Korea. Seoul: Daeyoung Moonhwasa.

Kim, P. S. (ed.) 2010. Civil Service System and Civil Service Reform in ASEAN Member Countries and Korea. Seoul: Daeyoung Moonhwasa.

Kim, P. S. (ed.) 2011. Public Sector Reform in ASEAN Member Countries and Korea. Seoul: Daeyoung Moonhwasa.

Pollitt, C. and Op de Beeck, L. 2010. Training Top Civil Servants: A comparative analysis. Leuven, Belgium: Public Management Institute of Katholieke Universiteit Leuven. 
This text is taken from Sharpening the Sword of State: Building executive capacities in the public services of the Asia-Pacific, edited by Andrew Podger and John Wanna, published 2016 by ANU Press, The Australian National University, Canberra, Australia. 